\title{
Bile acid secretion in cystic fibrosis: evidence for a defect unrelated to fat malabsorption
}

\author{
Z WEIZMAN, P R DURIE, H R KOPELMAN, SHIRLYM VESELY AND \\ G G FORSTNER \\ From the Gastrointestinal Division, Department of Paediatrics, and Cystic Fibrosis Research Centre, The \\ Hospital for Sick Children, Toronto, Canada
}

SUMMARY In order to define basic biliary defects not related to steatorrhoea in cystic fibrosis, we studied 12 control and 18 cystic fibrosis subjects, with a wide range of pancreatic function. Duodenal aspirates were collected over three consecutive 20 minute periods, during continuous intravenous infusion of cholecystokinin and secretin using a marker perfusion technique, and analysed for pancreatic enzyme output (colipase, lipase, trypsin), bile acid output and concentration, and biliary lipids. Cystic fibrosis patients, at all levels of pancreatic function, had significantly reduced total bile acid output $(\mu \mathrm{mol} / \mathrm{kg} / \mathrm{h})$ with delayed appearance of the bile acid peak, compared with control subjects. Actual duodenal bile acid concentrations were significantly higher in cystic fibrosis subjects than in controls, however, probably because of the markedly reduced water output shown in these patients. The lithogenic index was not raised in cystic fibrosis patients at any level of pancreatic function. The reduced bile acid output and the delayed peak appearance probably reflect a defect in gall bladder responsiveness which is independent of pancreatic function and steatorrhoea. Whether this defect is related to gall bladder filling or a defective peptide hormone response awaits further study.

Patients with cystic fibrosis are known to have a variety of bile acid abnormalities, including increased faecal bile acid losses, ${ }^{1-4}$ reduced bile acid pool size, ${ }^{5}$ reduced duodenal bile acid concentration $^{4}$ and increased bile salt glycine:taurine ratios. ${ }^{6}$ Cystic fibrosis bile has also been reported to be lithogenic. ${ }^{6}$ Almost all of the abnormalities appear to be associated with exocrine pancreatic insufficiency and steatorrhoea, and have been reported to become normal with an improvement of fat malabsorption after oral pancreatic enzyme therapy.

Approximately $10-15 \%$ of cystic fibrosis patients do not have steatorrhoea and our studies have shown that these patients possess a very wide range of exocrine pancreatic function with enzyme secretion ranging from $2-100 \%$ of normal values. ${ }^{7}$ Studies of biliary secretion in this cystic fibrosis population would be very helpful in clarifying pathophysiological mechanisms of bile secretion as

Address for correspondence: Dr Gordon Forstner. Cystic Fibrosis Research. The Hospital for Sick Children, 555 University Avenue. Toronto, Ontario M5G IXB. Canada.

Received for publication 17 January 1986 any defect would be independent of steatorrhoea. We have shown that these patients have defects in bicarbonate $^{8}$ and water ${ }^{9}{ }^{10}$ secretion which contribute to increased concentrations of protein in pancreaticobiliary secretions and possibly to ductal plugging. "' Unfortunately none of the previous studies related to bile acid secretion has attempted to correlate findings with the actual level of pancreatic function, and only limited data are available for cystic fibrosis patients without steatorrhoea. Weber et $a l^{3}$ showed that the faecal bile acid output of six cystic fibrosis patients without steatorrhoea was almost identical to that of controls. In contrast, a study of Fondacaro et $a l^{11}$ suggested that an ileal mucosal defect of taurocholic uptake was present in vitro.

In the present study we have analysed bile acid output during pancreatic function testing of cystic fibrosis patients who have a wide range of exocrine pancreatic function, including patients with and without steatorrhoea. Bile acid output in the cystic fibrosis patients has been compared with a group of subjects without cystic fibrosis who had a similar range of pancreatic function. 


\section{Methods}

\section{SUBJECTS}

We studied 18 patients with cystic fibrosis, aged $21 \cdot 7 \pm 6.9$ years (range $13-33$ years) and 12 subjects without cystic fibrosis aged $20.9 \pm 5 \cdot 6$ years (range 13-32 years). Male to female ratios in the two groups were 9:9 and 5:7 respectively. The diagnosis of cystic fibrosis was established by clinical symptoms and signs, chest roentgenograms and pulmonary function abnormalities, together with sweat chloride levels consistently greater than $60 \mathrm{mmol} / \mathrm{l}$. The 12 non-cystic fibrosis subjects in the control group consisted of four patients with Shwachman's syndrome, a patient with coeliac disease and exocrine pancreatic insufficiency, one patient, who after investigation had no gastrointestinal disease, and six normal volunteers. The normal volunteers were studied after approval by the Human Experimentation Committee of the Hospital for Sick Children, Toronto. Subjects with malnutrition or obesity were excluded. Fasting serum bile acid concentrations, serum bilirubin, alkaline phosphatase and SGOT were obtained in all patients and were within normal limits.

ASSESSMENT OF EXOCRINE PANCREATIC FUNCTION Faecal fat output was estimated in three to five day stool collections by the method of van der Kamer ${ }^{12}$ and expressed as percentage of fat intake determined by recording and weighing food and reference to standard content tables. For the purposes of this study, patients were divided into two groups. Patients with faecal fat output of more than $7 \%$ were defined as having pancreatic insufficiency and those with faecal fat less than or equal to $7 \%$ as having pancreatic sufficiency, indicating that they possessed sufficient residual pancreatic function to achieve normal fat absorption.

Pancreaticobiliary secretions were defined quantitatively by a stimulation test using a previously described technique. ${ }^{13}$ After an overnight fast, a double lumen tube was inserted into the duodenum under fluoroscopic control. The tube was constructed so that one lumen opened approximately at the ampulla of Vater and the other, which contained several ports, was positioned distally at the ligament of Treitz. Through the proximal opening, a nonabsorbable marker solution $(0.5 \mathrm{ml}$ bromosulphthalein in $250 \mathrm{ml}$ of $5 \%$ Mannitol) was infused into the duodenum at a constant rate of $1.6 \mathrm{ml} / \mathrm{min}$ throughout the test. Duodenal juice mixed with the marker solution was aspirated throughout the distal ports by intermittent Gomco suction (Gomco Surgical Manufacturing Corp, Buffalo, New York) and collected over four 20 minute collection periods into flasks on ice. After an initial 20 minute perfusion to remove duodenal content, duodenal aspirate was collected for three consecutive 20 minute periods during a continuous intravenous infusion of secretin and pancreozymin (Boots Pure Drug Company, Nottingham, UK), both at a dose of $0.125 \mathrm{U} / \mathrm{kg} /$ body weight $/ \mathrm{min}$. Throughout the test, gastric juice was aspirated through a separate nasogastric tube by low Gomco suction to prevent contamination of duodenal contents.

ASSAYS

Duodenal aspirates were analysed for colipase, lipase, and trypsin as described previously. ${ }^{7}$ Bromosulphthalein (BSP) concentration was determined by a colorimetric assay, ${ }^{14}$ so that the volume correction factor $\frac{\text { BSP infused }}{\text { BSP aspirated }}$ could be calculated. Pancreatic enzyme output was expressed in $\mathrm{U} / \mathrm{kg}$ body weight/h.

Duodenal bile acids were measured with a modified 3-alpha-hydroxysteroid dehydrogenase method. ${ }^{15}$ Cholesterol was determined as described by Carr and Drekter ${ }^{16}$ and phospholipid phosphorus by the method of Bartlett. ${ }^{17}$ All determinations were carried out in duplicate on separate aliquots. The lithogenic index for cholesterol was calculated as described. ${ }^{18}$ Bile acid output $(\mu \mathrm{mol} / \mathrm{kg}$ body weight $/ \mathrm{min}$ ) was determined by correcting for the fractional amount of BSP in the aspirate. The volume of pancreaticobiliary secretion was determined by subtracting the marker perfusion volume from the corrected aspirate volume. The concentration of bile acid in the secretions was then determined by dividing the bile acid output per 20 minute period by the secretion volume for the same period.

\section{STATISTICAL ANALYSIS}

All results were expressed as mean \pm SD. For statistical evaluation the Student's $t$ test, $\chi^{2}$ test and linear regression analysis were used.

\section{Results}

EXOCRINE PANCREATIC FUNCTION

A summary of pancreatic function data for all subjects is given in Table 1. Five cystic fibrosis patients had pancreatic insufficiency (CF-PI) and 13 had pancreatic sufficiency (CF-PS). Of the 12 subjects without cystic fibrosis, only two, a patient with Shwachman's syndrome and a patient with coeliac disease and associated exocrine pancreatic insufficiency, had steatorrhoea. As illustrated in Table 1, there was a wide range of pancreatic function for cystic fibrosis as well as for control subjects.

BILE ACID OUTPUT

The mean bile acid output per 20 minute collection 
Table 1 Range of exocrine pancreatic function in all subjects

\begin{tabular}{lrrccc}
\hline Subjects & & $n$ & Typsin output & Lipase output & Colipase output $^{*}$ \\
\hline Cystic fibrosis & PS & 13 & $16-1838$ & $220-15005$ & $120-12138$ \\
& PI & 5 & $0-4$ & $0-12$ & $0-15$ \\
\multirow{2}{*}{ Control } & PS & 10 & $19-3591$ & $323-45922$ & $188-30343$ \\
& PI & 2 & $2-51$ & $24-467$ & $9-81$ \\
\hline
\end{tabular}

${ }^{*}=$ units $/ \mathrm{kg} / \mathrm{h}$.

period is shown for all control, CF-PS and CF-PI subjects in Fig. 1. In the first two periods, output in both cystic fibrosis groups was significantly lower than that of the controls. As a group, the patients without steatorrhoea (CF-PS), like the control subjects, had the greatest bile acid output in the first period and the smallest bile acid output in the third period. The bile acid output in CF patients with steatorrhoea (CF-PI) changed relatively little from period to period.

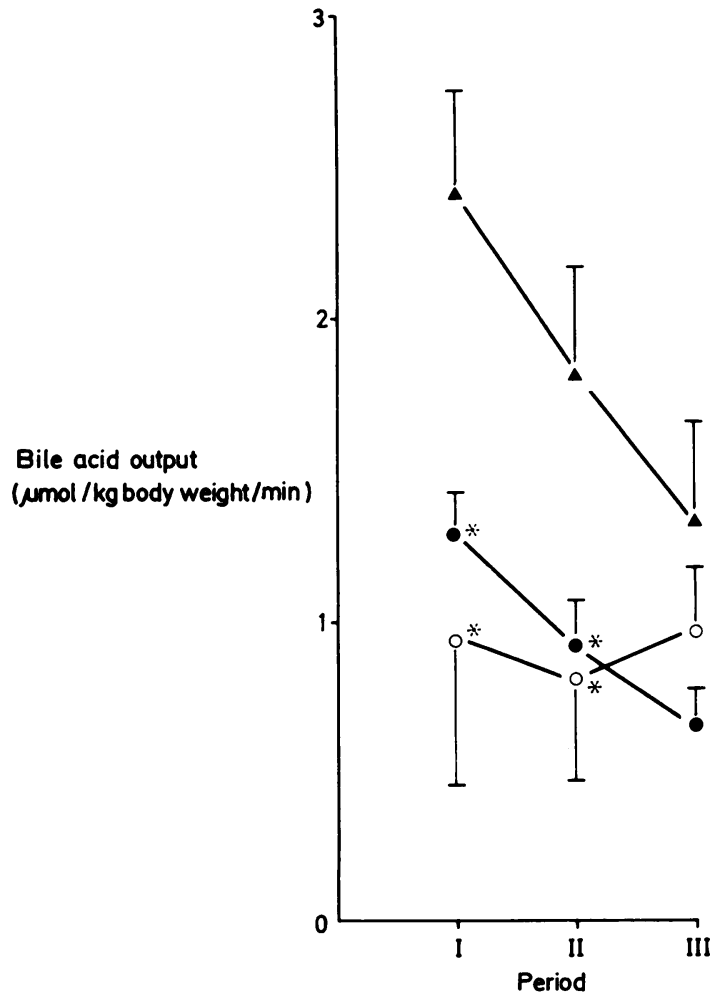

Fig. 1 Mean bile acid output data for the three periods for control subjects (A), CF-PS (O) and CF-PI (O) subjects, in periods I and II are significantly smaller in both cystic fibrosis groups than controls. ${ }^{*}=p<0.05$.
A comparison of individual bile acid output values in the three collection periods revealed that while eight of the $12(67 \%)$ control subjects showed a peak bile acid output in period I, only $5 / 18(28 \%)$ in the cystic fibrosis group showed a similar pattern $(p<0.02)$. Thus, most of the cystic fibrosis subjects had a late bile acid output peak, in period II or III, or no peak at all. Bile acid output values for cystic fibrosis subjects were significantly reduced when compared with non-cystic fibrosis values, for either total bile acid output from all three periods (Fig. 2a) or peak bile acid output (Fig. 2b), $(p<0.001$ and $\mathrm{p}<0.01$ respectively). Regression analyses performed for total bile acid output or peak bile acid output against age or several pancreatic function parameters (colipase, lipase or trypsin output) revealed no correlation $(r<0 \cdot 2, p=N S)$. There was a significant correlation when total bile acid output was plotted versus total water output $(r=0 \cdot 50$, $\mathrm{p}<0.01)$.

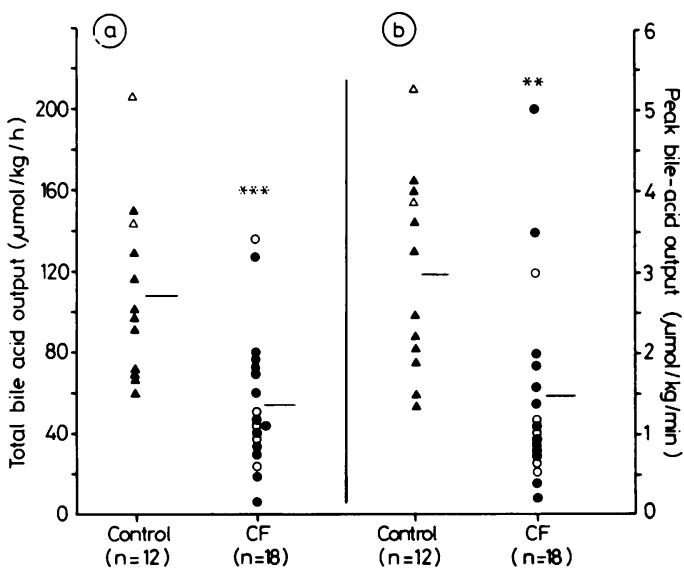

Fig. 2 Total bile acid output $(A)$ and peak bile acid output $(B)$ in control subjects without steatorrhoea $(\mathbf{\Delta})$ and control subjects with steatorrhoea ( $\triangle), C F-P S(O)$, and CF-PI (O) subjects. Means are indicated by short horizontal lines. Total and peak bile acid output were significantly lower in cystic fibrosis patients. ${ }^{* *}=p<0.01$, $* * *=p<0.001$. 
BILE ACID CONCENTRATION

As illustrated in Table 2, mean bile acid concentrations in both CF-PS and CF-PI samples were significantly higher than in control samples $(p<0 \cdot 02$ and $p<0.05$ respectively). When compared with controls, water output was significantly reduced in both CF-PS and CF-PI patients $(\mathrm{p}<0.0001$ for both).

\section{BILE LITHOGENICITY}

Mean lithogenic indices for individual periods and for the period with the highest bile acid output are given in Table 3. Although mean values in the CF-PI patients are lower than the means for control and CF-PS patients, this difference did not reach statistical significance. There was no significant difference between control and cystic fibrosis values.

Bile acid output values for all three periods were plotted against lithogenic index (Fig. 3). The overall pattern for both non-CF and CF subjects ( 36 and 54 data points respectively) revealed little change in lithogenicity over a wide range of bile acid output. Exceptionally high indices were found in only three samples, all in periods with very low bile acid outputs. The high values were from aspirates in period III from three different normal volunteers. With the exception of these values, there was no correlation between bile acid output and lithogenicity in either the cystic fibrosis or non-cystic fibrosis samples. No correlation was found as well between lithogenic index and age or trypsin, lipase, and colipase output.

Table 2 Duodenal bile acid (BA) concentration and water output data

\begin{tabular}{lrcl}
\hline Subjects & $n$ & $\begin{array}{l}\text { BA concentration } \\
(\mathrm{mmol} / \mathrm{l})\end{array}$ & $\begin{array}{l}\text { Water output } \\
(\mathrm{ml} / \mathrm{kg} / \mathrm{h})\end{array}$ \\
\hline Control & 12 & $\begin{array}{c}8 \cdot 2 \pm 5 \cdot 6 \\
16 \cdot 6 \pm 9 \cdot 8 \div\end{array}$ & $\begin{array}{l}7 \cdot 5 \pm 2 \cdot 0 \\
\text { CF-PS }\end{array}$ \\
CF-PI & 13 & $36.4 \pm 29 \cdot 4^{*}$ & $0.9 \pm 1 \cdot 2 \ddagger$ \\
\hline
\end{tabular}

From controls ${ }^{*} \mathrm{p}<0.05, \div \mathrm{p}<0 .(0) 02, \quad \neq \mathrm{p}<0 \cdot 0001$.

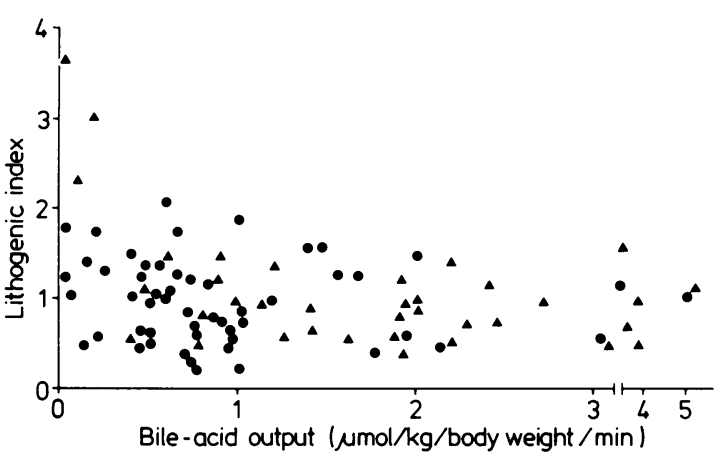

Fig. 3 relation between bile acid output and lithogenic index in cystic fibrosis (O) and control ( $\mathbf{\Delta})$ subjects.

\section{Discussion}

We have shown that bile acid output is significantly reduced in cystic fibrosis patients when compared with control subjects. Furthermore, the peak bile acid output per 20 minute period is significantly lower in cystic fibrosis patients and peak rates of bile acid output are attained more slowly after stimulation. Cystic fibrosis patients with normal fat absorption as well as patients with steatorrhoea exhibited these defects indicating that they are not related to pancreatic insufficiency. The significant correlation between water output and bile acid output supports this conclusion, because we have previously shown a decreased water output in cystic fibrosis, independent of pancreatic function. ${ }^{10}$

Previous studies have described several gall bladder abnormalities in cystic fibrosis, such as hypoplastic gall bladder, ${ }^{19} 20$ mucosal hyperplasia with stenosis of the cystic duct, ${ }^{21}$ and poor visualisation of the gall bladder on radiological studies. ${ }^{62}$ We believe the present defect is probably a reflection of poor gall bladder response to cholecystokinin in cystic fibrosis because of anatomical and physiological changes in this organ. Although our studies pertain only to exogenous stimulation by cholecystokinin, endogenous secretion of cholecystokinin is probably adequate in

Table 3 Comparison of lithogenic indices in the three periods and in peak bile acid output (BAO) period

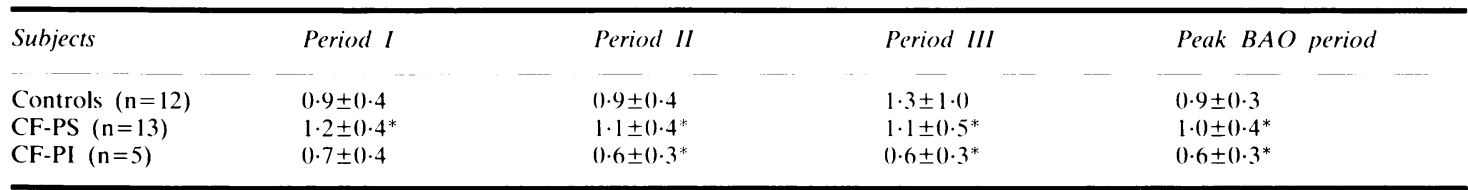

From controls, ${ }^{*} p=$ not significant. 
cystic fibrosis, as it has been recently reported that endogenous release of this hormone showed no significant difference from controls. ${ }^{23} \mathrm{~A}$ poor contractile response, however, may not be the only cause for diminished bile acid output in cystic fibrosis, as reduced filling of the gall bladder could have a similar effect. A primary ileal mucosal defect in bile acid uptake, as suggested by Fondacaro et al ${ }^{11}$ might affect bile-acid pool size and gall bladder filling and cannot be excluded. Other parameters of bile acid kinetics like bile acid pool size, recycling frequency of bile acids and bile acid profile $(G / T$ ratio, trihydroxy/dihydroxy ratio etc) have not been studied in CF-PS patients and should be evaluated in future studies.

After an overnight fast most of the bile acid pool is stored in the gall bladder, awaiting an adequate stimulus for gall bladder contraction in order to be secreted into the duodenum. ${ }^{24}$ The dose of pancreozymin administered during our stimulation test was previously shown to cause a significant contraction of the gall bladder in normal subjects, resulting in peak bile acid output. ${ }^{25}$ It should be noted that the aspiration of duodenal content throughout the present study (under 80 minutes) should not affect bile acid output results because of interruption of the enterohepatic circulation as previous studies in normal individuals have shown that acute interruption of the enterohepatic circulation only interferes with bile acid secretion rate after 90 minutes. ${ }^{26}$

In view of the significant reduction in bile acid output in cystic fibrosis subjects, we have evaluated the actual bile acid concentration throughout the present study. Mean bile acid concentration in cystic fibrosis patients was significantly higher than controls. As we have previously shown, cystic fibrosis subjects have reduced water output at all levels of pancreatic function. ${ }^{910}$ High bile acid concentrations are therefore probably the result of poor water output. As total bile acid output is reduced they do not necessarily reflect the CMC achieved during a meal. Data regarding postprandial bile-acid concentration values in cystic fibrosis are limited. Goodchild $e t a l^{2}$ showed a mean postprandial duodenal total bile acid concentration that was within normal limits in five CF-PI patients. In contrast, a study by Harries et $a l^{4}$ described normal postprandial duodenal bile acid concentrations in two CF-PS patients, while two out of 11 CF-PI subjects revealed reduced concentrations.

Cholesterol gall stones are a well recognised complication of cystic fibrosis. ${ }^{6}$ The bile of CF-PI patients has been reported to be supersaturated with cholesterol and lithogenic. ${ }^{6}$ Lithogenicity of bile, however, has never been evaluated in CF-PS subjects. In the present study, no significant differences in lithogenicity were found when cystic fibrosis and control individuals were compared. Poststimulation duodenal bile is considered to be mainly of gall bladder origin, ${ }^{25}$ especially during the period of peak bile acid output, and therefore accurately represents the relative lipid composition of gall bladder bile. ${ }^{27}$ Thus, our data fail to show significant lithogenicity of cystic fibrosis gall bladder bile.

The three subjects who had very lithogenic bile during the period with lowest bile acid output (Fig. 3) presumably represent sampling of hepatic bile. During continuous stimulation the gall bladder remains tonically contracted with secretion of hepatic bile into the duodenum. ${ }^{28}{ }^{29}$ Hepatic bile is well known to be oversaturated with cholesterol. ${ }^{30}$ Only one cystic fibrosis subject had a lithogenic index greater than 2 , and this occurred without a diminished bile acid output. Surprisingly, CF-PI patients showed a mean lithogenic index smaller than CF-PS or control individuals. These results for CF-PI subjects are not in agreement with data presented by Roy et at , who showed an abnormally high molar percentage of cholesterol in fasting CF-PI bile which disappeared after pancreatic enzyme therapy, suggesting that it was secondary to steatorrhoea. Our results could represent real differences between the groups of patients studied or the different design of the two studies. Roy et al suspended pancreatic enzyme therapy for one week before testing while our patients stopped this therapy only 48 hours before the study. It is possible that the $\mathbf{4 8}$ hour time interval was insufficient to reverse the effect of enzyme therapy. It should be noted, however, that our CF-PS patients were not on enzyme therapy. These patients had no evidence of lithogenic bile. Cholesterol supersaturation, when seen, therefore is probably a secondary result of untreated pancreatic steatorrhoea. Cholesterol supersaturation may not be the only cause of gall stones in cystic fibrosis. Other potential mechanisms such as abnormal gall bladder mucin, as shown in the small intestine,${ }^{31}$ and high protein content of pancreaticobiliary secretion, ${ }^{10}$ may play a role in gall stone formation in cystic fibrosis and should be evaluated in future studies.

We are grateful for the thoughtful advice provided by $\mathrm{Dr}$ Steven Strasberg with regard to bile salt analyses.

\section{References}

1 Weber AM, Roy CC, Morin CL, Lasalle R. Malabsorption of bile acid in children with cystic fibrosis. $N$ Engl J Med 1973; 289: 1001-5. 
2 Goodchild MC, Murphy GM, Howell AM, Nutter SA, Andersen CM. Aspects of bile acid metabolism in cystic fibrosis. Arch Dis Child 1975; 50: 769-78.

3 Weber AM, Roy CC, Chartrand L et al. Relationship between bile acid malabsorption and pancreatic insufficiency in cystic fibrosis. Gut 1976; 17: 295-9.

4 Harries JT, Muller DPR, McCollum JPK, Lipson A, Roma E, Norman AP. Intestinal bile salts in cystic fibrosis. Arch Dis Child 1979; 54: 19-24.

5 Watkins JB, Tercyak AM, Szczepanik P, Klein PD. Bile salt kinetics in cystic fibrosis: Influence of pancreatic enzyme replacement. Gastroenterology 1977; 73: 1023-8.

6 Roy CC, Weber AM, Morin CL et al. Abnormal biliary lipid composition in cystic fibrosis: Effect of pancreatic enzymes. $N$ Engl J Med 1977; 297: 1301-5.

7 Gaskin KJ, Durie PR, Lee L, Hill R, Forstner GG. Colipase and lipase secretion in childhood-onset pancreatic insufficiency. Gastroenterology 1984; 86: 1-7.

8 Gaskin KJ, Durie PR, Corey M, Wei P, Forstner GG. Evidence for a primary defect of pancreatic $\mathrm{HCO}_{3}$ secretion in cystic fibrosis. Pediatr Res 1982; 16: 554-7.

9 Kopelman H, Corey M, Gaskin K, Durie P, Forstner $G$. Impaired pancreatic water secretion in cystic fibrosis is independent of pancreatic dysfunction. [Abstract]. Clin Invest Med 1983; 6: 50.

10 Kopelman $\mathrm{H}$, Durie P, Gaskin KJ, Weizman Z, Forstner GG. Pancreatic fluid secretion and protein hypersecretion in cystic fibrosis. $N$ Engl J Med 1985 ; 312: 329-34.

11 Fondacaro JD, Heubi JE, Kellogg FW. Intestinal bile acid malabsorption in cystic fibrosis: a primary mucosal cell defect. Pediatr Res 1982; 16: 494-8.

12 Van der Kamer JH, Huinick H, Weyers HA. Rapid method for determination of fat in feces. $J$ Biol Chem 1949; 177: 347-51.

13 Go VLW, Hoffman AF, Summerskill WHJ. Simultaneous measurements of total pancreatic, biliary and gastric outputs in man using a perfusion technique. Gastroenterology 1970; 58: 321-8.

14 Seligson D, Marino J, Dodson F. Determination of sulfobromophthalein in serum. Clin Chem 1957; 3: 638-45.

15 Talalay P. Enzymic analysis of steroid hormones. Meth Biochem Anal 1960; 8: 119-43.

16 Carr JJ, Drekter IJ. Simplified rapid technique for the extraction and determination of serum cholesterol without saponification. Clin Chem 1956; 2: 353-68.

17 Bartlett GR. Phosphorus assay in column chromatography. J Biol Chem 1959; 234: 466-8.
18 Thomas PJ, Hofmann AF. A simple calculation of the lithogenic index: Expressing biliary lipid composition on rectangular coordinates. Gastroenterology 1973; 65: 698-700.

19 Feigelson J, Mareschal JL, Sauvergain J. Les anomalies de la vesicule biliaire dans la mucoviscidose. A propos de 57 observations. Med Chir Dig 1975; 4: 121-4.

20 Isenberg J, L'Hereux P, Warwick W, Sharp H. Clinical observations on the biliary system in cystic fibrosis. $\mathrm{Am}$ J Gastroenterol 1976; 65: 134-41.

21 Oppenheimer EH, Esterly JR. Pathology of cystic fibrosis: Review of the literature and comparison with 146 autopsied cases. Perspect Pediatr Pathol 1975; 2: 24-32.

22 Hubbard VS, Head GL, Shawker TH, di Sant'Agnese PA. Radiological and ultrasound evaluation of the gallbladder in patients with cystic fibrosis [Abstract]. Pediatr Res 1978; 12: 437.

23 Allen JM, Penketh ARL, Adrian TE et al. Adult cystic fibrosis: postprandial response of gut regulatory peptides. Gastroenterology 1983; 85: 1379-83.

24 Shaffer EA, Braasch JW, Small DM. Bile composition at and after surgery in normal persons and patients with gallstones. $N$ Engl J Med 1972; 287: 1317-22.

25 Malagelada JR, Go VLW, Summerskill WHJ. Differing sensitivities of gallbladder and pancreas to cholecystokinin-pancreozymin in man. Gastroenterology 1973; 64: 950-4.

26 Dowling RH, Mack E, Small DM. Effects of controlled interruption of the enterohepatic circulation of bile salts by biliary diversion and by ileal resection on bile salt secretion, synthesis and pool size in the rhesus monkey. J Clin Invest 1970; 49: 232-42.

27 Vlahcevic ZR, Bell CC, Juttijudata P, Swell L. Bile-rich duodenal fluid as an indicator of biliary lipid composition and its applicability to detection of lithogenic bile. Dig Dis 1971; 16: 797-805.

28 Shaffer EA, Small DM. Biliary lipid secretion in cholesterol gallstone disease: The effect of cholecystectomy and obesity. J Clin Invest 1977; 59: 828-40.

29 Sama C, LaRusso NF, Del Pino VL, Thistle JL. Effects of acute bile acid administration on biliary lipid secretion in healthy volunteers. Gastroenterology 1982; 82: 515-25.

30 Van der Linden W, Nakayama F. Hepatic versus duodenal bile. Scand J Gastroenterol 1982; 17: 497-502.

31 Forstner J, Wesley A, Mantle M, Kopelman H, Man D, Forstner GG. Abnormal mucus: Nominated but not yet elected. J Pediatr Gastroenterol Nutr 1984; 3 Suppl 1: S67-73. 